\title{
Measuring study time distributions: Implications for designing computer-based courses
}

\author{
ROMAN TARABAN, WILLIAM S. MAKI, and KIMBERLY RYNEARSON \\ Texas Tech University, Lubbock, Texas
}

\begin{abstract}
In both traditional lecture-test courses and courses delivered over the World-Wide Web (WWW), both beginning and experienced college students reported studying almost exclusively just before exams. Automatic measures (computer records, WWW page hits, and electronic mail archives) confirmed the self-reported distributions of study times. Weekly deadlines produced weekly volleys of taking on-line quizzes, a pattern that was reflected in self-reports of study times. However, on-line study materials were used primarily for review for regularly scheduled in-class exams. Thus, regardless of course format, students engaged in massed practice and did not experience study aids at appropriate times. Computer technology provides new forms of learning for students, as well as opportunities for instructors to observe patterns of student study time. Management of instructional contingencies will be necessary to bring students into contact with the rich cognitive aids enabled by technology.
\end{abstract}

As the world's population increases and as the demographics of student populations change, there is an increasing need to rework our educational practices to make them more effective and efficient (see, e.g., Barr \& Tagg, 1995; Bork, 1997). Advances in computers and information technologies are seen to be a cornerstone of educational change (see, e.g., Bork, 1997), and emerging technologies now offer the hope of providing rich learning aids to students at a distance (Dede, 1996). However, anecdotal lore suggests that what students actually do is often at odds with what the instructor intends them to do. The data reported in this paper were gathered in differently formatted courses and confirm the suspicion that students behave in ways that do not bring them into contact with the instructional activities and cognitive aids that are produced for them. Traditional classroom contingencies encourage massed practice-for example, resulting in concentration of study and course work just prior to scheduled exams. Thus, common educational practices and students' adaptations to them threaten to blunt the impact of new educational technology.

Students' use of course materials was measured in three types of courses taught at a large public university (Texas Tech). Three cases from psychology are presented: (1) traditional lecture-test courses at both beginning and advanced levels, (2) an upper level course augmented with computer-based exercises and presentations, and (3) a beginning level course taught mostly over the World-Wide Web (WWW). The measures ranged from pure self-

Partial support for the development and evaluation of the Web-based General Psychology course (reported as Case 3) was provided by the National Science Foundation Grant DUE 9752349 to Ruth H. Maki and W.S.M. Correspondence concerning this article should be addressed to R. Taraban or W. S. Maki, Department of Psychology, Texas Tech University, Lubbock, TX 79409-2051 (e-mail: tirmt@ttacs.ttu.edu or maki@ttu.edu). report of study times to automatically collected date-timestamped electronic records of computer-based course work. This report describes the characteristics of the studied courses, summarizes the measures and results, and concludes with some implications for the design of instruction that uses computers.

\section{CASE 1 \\ Self-Reports of Study Time in a Traditional Lecture-Test Class}

\section{Method}

A three-item paper-and-pencil questionnaire was developed in order to gather self-reports of total estimated study time, to determine how students distributed their study time, to establish whether they thought that their study behaviors differed from their peers' study times, and to determine how students' times compared with those of an ideal student. Two versions of the questionnaire were used. One group of students received a version that asked them to estimate the average number of minutes per day that they, other students, and an ideal student spent preparing for a test over a 13-day interval between two tests in a typical undergraduate psychology course. Another group of students received a version that asked them to estimate how much time they, other students, and an ideal student spent preparing for class across the same 13-day interval. For each version, the students estimated their day-by-day study time ("How much time do you spend preparing?"), the day-by-day study time of other students at their level ("What do you think other students at your level [e.g., freshman, sophomore, etc.] do?"), and an ideal student's day-by-day study time between tests ("What is the ideal amount of time a student should spend preparing?").

The questionnaire was administered to 99 undergraduates, who were recruited through two lecture-based courses, Introductory Psychology and Personality. All the students who were present in class on the day that the questionnaire was distributed were invited to participate. Participation was voluntary, and the students provided responses anonymously. Questionnaire versions were distributed to participants in alternating fashion. The order of the three questions was counterbalanced across questionnaires, to control for order effects among the items. After data collection, seven response sheets were discarded because of ambiguous responses. The participants 
contributing data were 41 freshmen, 22 sophomores, 21 juniors, and 8 seniors.

\section{Results and Discussion}

An analysis of variance (ANOVA), using questionnaire version (preparing for test, preparing for class), days since last test (1-13), and question (self, other, ideal) showed that it did not matter whether the questions were worded in terms of preparing for class or preparing for a test. The main effect for questionnaire version and the associated interactions were not statistically significant (all $F \mathbf{s}<1$ ). Thus, the remaining analyses ignore questionnaire version.

Figure 1A shows the mean total times per student (in minutes) that students reported that they would study for

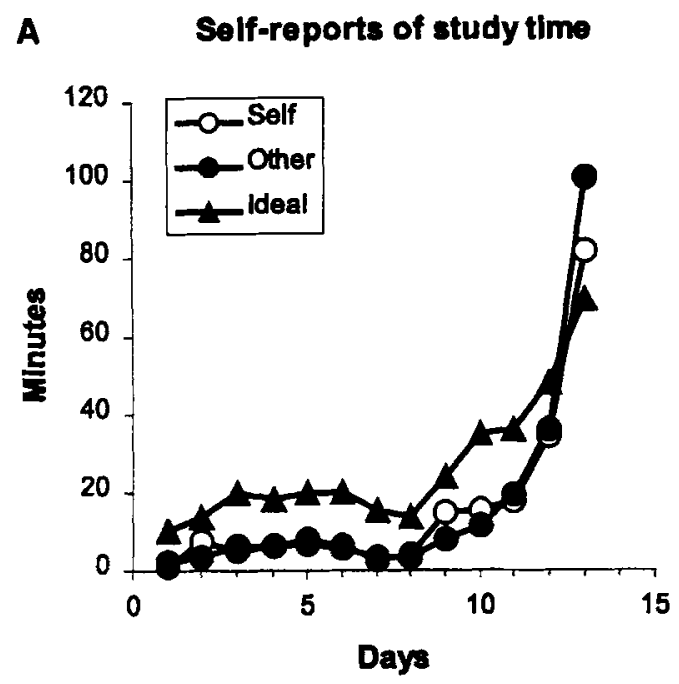

\section{B Self-reports of study time (by class)}

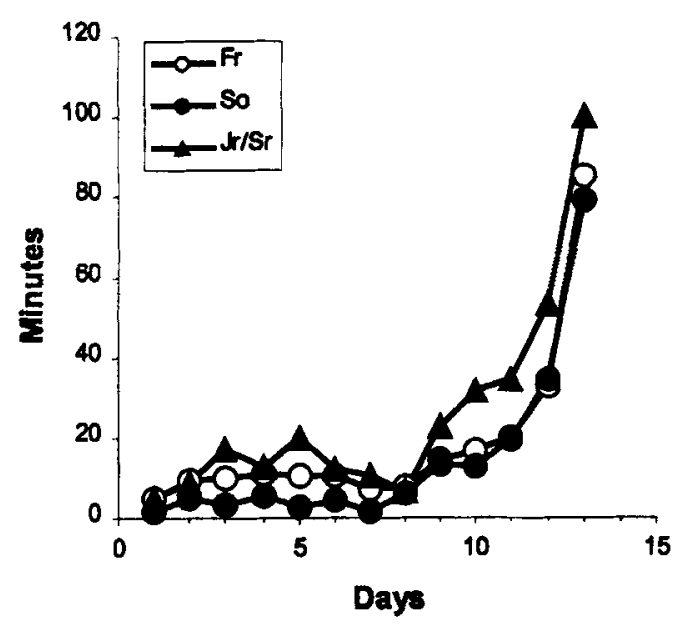

Figure 1. (A) Mean times per student (in minutes) for each of the 13 days between hypothetical exams for the self, other students, and ideal student items on the questionnaire. (B) Mean times per student (in minutes) for each of the 13 days between typical tests in psychology by academic classification (freshman, sophomore, junior-senior). a typical psychology test on each of the 13 days between tests. The main effect for the day of study was significant $\left[F(12,1092)=111.32, M S_{\mathrm{e}}=1,147.67, p<.001\right]$. As is clear in Figure 1A, the students reported allocating the majority of their study time to the 2 days before the test.

The differences between questions (for self, other students, and an ideal student) also were significant $\left[F(2,182)=31.23, M S_{\mathrm{e}}=1,342.94, p<.001\right]$, as was the interaction of question and day $[F(24,2184)=10.91$, $\left.M S_{\mathrm{e}}=369.13, p<.001\right]$. As is suggested by Figure 1A, the students thought that they spent about the same amount of time on class materials as other students and that the ideal student spent more time than either group did. Post hoc comparisons were performed, using Tukey's HSD procedure (with $\alpha=.05$ ). The mean time per day for self $(M=15.79 \mathrm{~min})$ was not significantly different from the mean time per day for others $(M=16.37 \mathrm{~min})$, but the mean time per day for the ideal student $(M=$ $26.32 \mathrm{~min}$ ) was significantly different from the mean times for self and other students. Visual inspection of Figure 1A suggests that the significant interaction between question and day was due to students' perception that other students would cram more than they did the day before the test and that the ideal student would cram least of all.

The data were also examined for differences between freshmen, sophomores, juniors, and seniors. Because the senior sample size was small $(n=8)$, juniors and seniors were combined into one classification group of juniorsseniors. There were no significant interactions between classification groups and questionnaire versions or questions $(F \mathrm{~s}<1.20)$, so the data were averaged across these factors and are shown in Figure 1B. Freshmen, sophomores, and juniors-seniors differed from one another $\left[F(2,89)=4.29, M S_{\mathrm{e}}=7994.99, p<.05\right]$. As is evident in Figure 1B, juniors-seniors reported more study time than freshmen or sophomores, who were similar. Using Tukey's HSD procedure $(\alpha=.05)$, the mean time per day for juniors-seniors ( $M=25.76 \mathrm{~min})$ was significantly greater than the mean time for sophomores $(M=$ $14.93 \mathrm{~min}$ ) but did not differ from that for freshmen $(M=17.51 \mathrm{~min})$. The pattern of massed practice immediately before a test was present for juniors and seniors, as well as for freshmen and sophomores.

These self-reports present a startling picture of student study times. The average reported total study time was $3.42 \mathrm{~h}$ across the 13 days. This is approximately $15 \mathrm{~min}$ per day. As was already noted, these results hold whether one asks students about preparing for a class or preparing for a test. When asked about the ideal student, study times were not a great deal higher-an ideal student devoted about $25 \mathrm{~min}$ a day to studying for a class or preparing for a test. A consistent pattern across all these data is that the students reported minimal study time up until the day before the test - for themselves, for other students, and for an ideal student.

The questionnaire data were collected from students whose primary study materials were class notes and a textbook. These preliminary data set the stage for the 
next two studies, in which students accessed a portion of their course materials over the WWW. It was therefore possible to gather objective data automatically from student interactions with the computer-based materials and to compare these data with students' self-reports.

\section{CASE 2 \\ Measures of Study Time With Computer-Based Presentations and Exercises}

\section{Method}

Cognition is an upper level undergraduate course for psychology majors. The topics are drawn from cognitive psychology and include perception, memory, categorization, natural language processing, problem solving, decision making, intelligence, and the development of expertise. Course material includes reports of experiments, text describing the theories that these experiments address, various notations for representing knowledge and cognitive processes, and models of cognition.

Computer lessons were delivered to students via the WWW (Taraban \& Rynearson, 1998). The home page and main menu screens for this course can be accessed (at http://www.cognition.ttu.edu). The screens were created with the Authorware authoring software.

The lessons were a core part of the course, and the students were tested over the material covered in these lessons. The lessons were menu driven and self-paced. When the students opened a lesson, several menu bars appeared, which allowed the students to selectively access topics within the lesson. Lessons consisted of text about several topics and interactive activities. The interactive activities required the students to label diagrams, compute activation values in neural networks, compute probabilities, and provide short answers to questions about a variety of topics. For the majority of activities, the computer gave the students immediate feedback about their accuracy. In the case of computations, such as probabilities, the computer also allowed the students to practice calculations as often as they wished, using new sets of random values. In addition, the screen often gave pointers to pages in the textbook for the course and provided additional comments or definitions that the students accessed by clicking on "hot spots" on the screen. The computer automatically created a record of the students' interactions (with the students' knowledge and permission) on the client machine as they read through the texts and interacted with the activities. When the students exited a lesson, the data were transferred automatically to the course server, using FTP routines. Thus, it was possible to observe the amount of time that the students spent and the distribution of those times. Toward the end of the semester, the students were also asked to complete the questionnaire described earlier. The low $N$ precluded administering both versions of the questionnaire; the preparing for a test version was used.

\section{Results and Discussion}

The data that are presented here are for the 16 (out of 20 ) students who completed the questionnaire. Figure $2 \mathrm{~A}$ presents a summary of the students' responses to the three questionnaire items. The data points indicate mean total study times (in minutes) per student for each of the 13 days prior to a typical test in psychology. The patterns of these students' responses were similar to those of the larger noncomputer group presented earlier. Judgments about self and the other students were similar. An ANOVA, using question (self, other, ideal), showed a significant effect for this factor $\left[F(2,30)=4.14, M S_{\mathrm{e}}=153.54, p<\right.$ $.05]$. Follow-up tests using Tukey's HSD procedure $(\alpha=$ .05 ) showed that the mean time per day attributed to the

\section{A Study time: Self-roports vs. actual use}
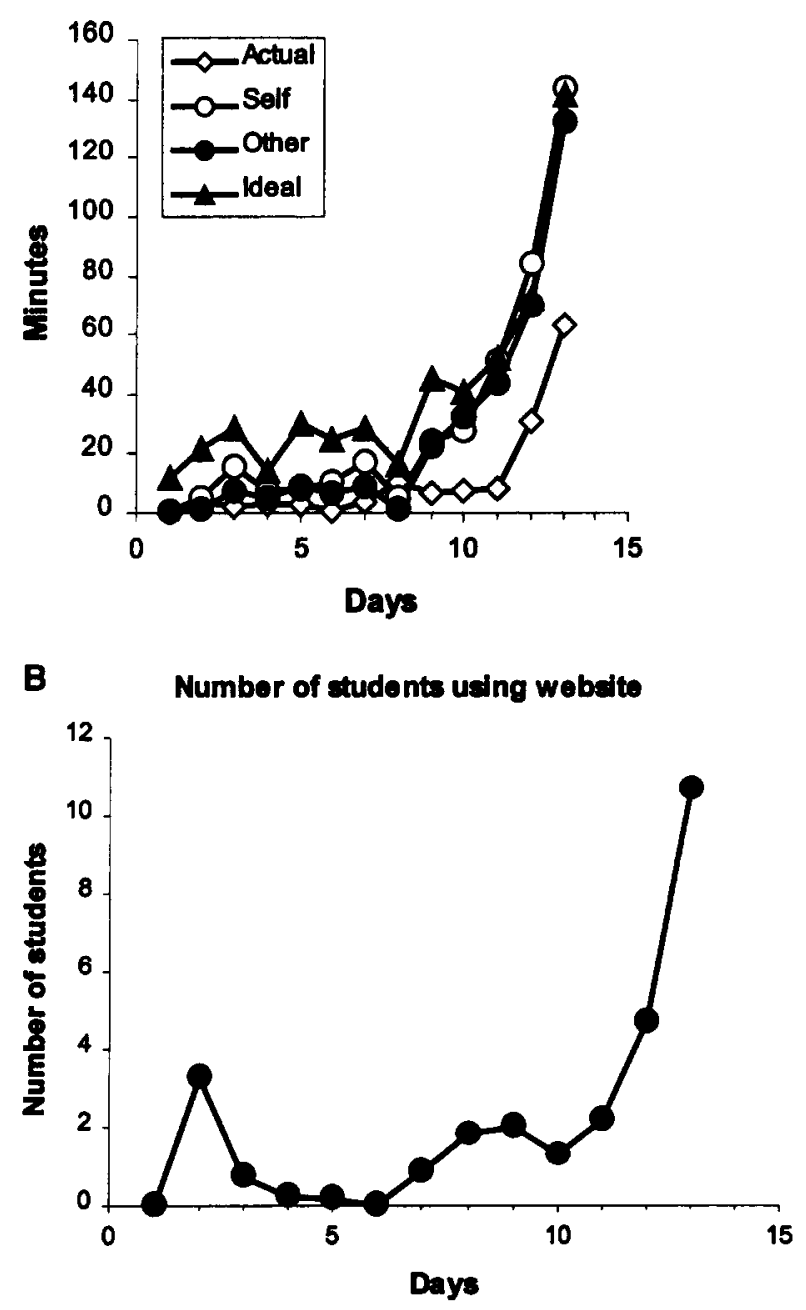

Figure 2. (A) Mean total times per student (in minutes) for each of the 13 days between typical tests in psychology for the three items on the questionnaire (self, other, ideal) and mean actual time (in minutes) per student $(N=16)$ logged by the computer for each of the 13 days between tests (averaged across six tests). (B) The total number of students (averaged across six tests) accessing the computer lessons for each of the 13 days between tests.

ideal student $(M=38.68 \mathrm{~min})$ differed significantly from the mean time for other students $(M=26.18 \mathrm{~min})$ but did not differ from the mean time attributed to self $(M=30.99 \mathrm{~min})$. Thus, other students, but not the students giving the self-reports, were thought to spend significantly less time studying, as compared with an ideal student.

Figure 2A also presents the students' actual time at the computer. The data points indicate the mean total study time (in minutes) per student for each of the 13 days prior to an exam, averaged across six exams in the course. One thing to note is that the mean total time at the computer $(2.25 \mathrm{~h}$ per student per exam) is about one-third of the total study time that students reported on the questionnaire $(6.72 \mathrm{~h})$. The questionnaire times may reflect study 
time from notes, which would not show up in the computer times. It is also possible that the students did not accurately report their study times.

Figure 2B shows the total number of students accessing the computer lessons (averaged across six exams) on each day prior to an exam. It is clear that only a minority of the students accessed the computer lessons early on in an exam cycle. (The exception on Day 2 in Figure 2B is due primarily to a brief introductory meeting at which students practiced logging into the computer lessons.)

If we use the lower estimate of study time, the students in this course averaged roughly $10 \mathrm{~min}$ per day between tests. If we use the higher estimate, they averaged approximately 30 min per day. Assuming a course load of four courses like this one, the lower estimate would yield an estimate of total study time outside of class of only $40 \mathrm{~min}$ per day! The higher estimate would yield about $2 \mathrm{~h}$ per day.

Figure $2 \mathrm{~A}$ is striking because of the way in which the distribution of actual study time closely mirrors these students' questionnaire responses. Even if the students were not accurate in judging the absolute time they spent studying, they were accurate in depicting the relative distribution of time. In order to confirm the correlation between the four curves in Figure 2A, Pearson correlation coefficients were computed. All coefficients were high and significant [smallest $r(11)=.95, p<.01]$. The significant coefficients indicate that the students believed that all the students generally distributed their study time in a similar manner. The correlation coefficients also show that the patterns of students' behaviors were congruent with their beliefs about how they and other students study.

\section{CASE 3}

\section{Measures of Study Time in a Web-Based Course}

\section{Method}

General Psychology is a freshman course in psychology and is taken by students from a broad range of disciplines in the university (see http://ttacs7.ttu.edu:8902/ psy1300). Lectures were replaced by three required activities (W. S. Maki \& R. H. Maki, 1997). The students took weekly quizzes, wrote weekly assignments, and met in class once a week for a lab project or demonstration. Quizzes consisted of 15 questions each, randomly drawn (with replacement) from a pool of questions supplied by the publisher of the textbook. Completion of each activity before the weekly deadline earned points counting toward the course grade. Each week students could earn credit for up to four quizzes passed (at or above $70 \%$ correct). The quizzes and assignments were administered using the WWW, and quiz results and assignment feedback were communicated by email, thus leaving an electronic trail.

E-mail archives were managed with Eudora Pro, a commercial mail system (see http://www.eudora.com) and a set of scripts written in Perl (Wall, Christiansen, \& Schwartz, 1998). For example, each quiz was scored by one script residing on the server, the results were e-mailed to the course instructor, and the resulting local mailbox file was parsed by another Perl script running on the instructor's personal computer. Quizzes both attempted and passed were tallied for each day. Schwartz (1998), in this journal, provided a tutorial on Perl for psychologists and a list of resource books (e.g., Wall et al., 1998). In addition, scripting in Perl for WWW applications is greatly facilitated by using a library of predefined methods; CGI.pm (Stein, 1998) was used in the scripts mentioned here.
Course information (e.g., syllabi, grading policies, and a "What's new" page) and study aids (chapter outlines and answers to frequently asked questions [FAQs] were posted at the Web site. An invisible counter was included on each web page containing these materials. (Web page hits were recorded with Count 2.0; see http://www. fccc.edu/users/muquit/Count.html). The first entry to a Web page during a browser session incremented that page's counter. The students were advised several times during the course to use the on-line syllabus as a link to the coursework pages, to monitor the "What's New" page for news about the course, and to use the outlines and FAQs as advance organizers to guide their study of the chapter assigned for the week.

The course was organized into four units. Each of the first three units covered three chapters from the textbook and the fourth unit included four chapters. Prior to the start of the first unit, the students attended training sessions on use of WWW browsers and email. An in-class exam was scheduled at the end of each of the first three units, and an in-class final exam concluded the fourth unit.

One question was whether the weekly quizzes and assignments would influence students' reports of study time distributions. At the end of the course, the students were given the test-preparation version of the study time questionnaire, modified to ask for study time estimates for each day during a typical 3-week exam cycle.

\section{Results and Discussion}

Self-reports of study times for 20 students who completed the questionnaire are shown in Figure 3. The patterns of study times were similar for estimates of self, other, and ideal; all three measures were significantly intercorrelated [smallest $r(18)=.89, p<.01$ ]. In all three cases, the amount of study time reported was highest during the 2 days prior to the exam. This is the same pattern as that shown in the other two course formats. However, a cyclical weekly pattern was superimposed on the longer pattern spanning the 3 weeks prior to each exam. These weekly peaks (at Days 4 and 11) corresponded to the weekly deadlines for quizzes and assignments for the first two chapters of each unit. Thus, in their self-reports, the students were sensitive to the nested structure of quizzes and exams in the course.

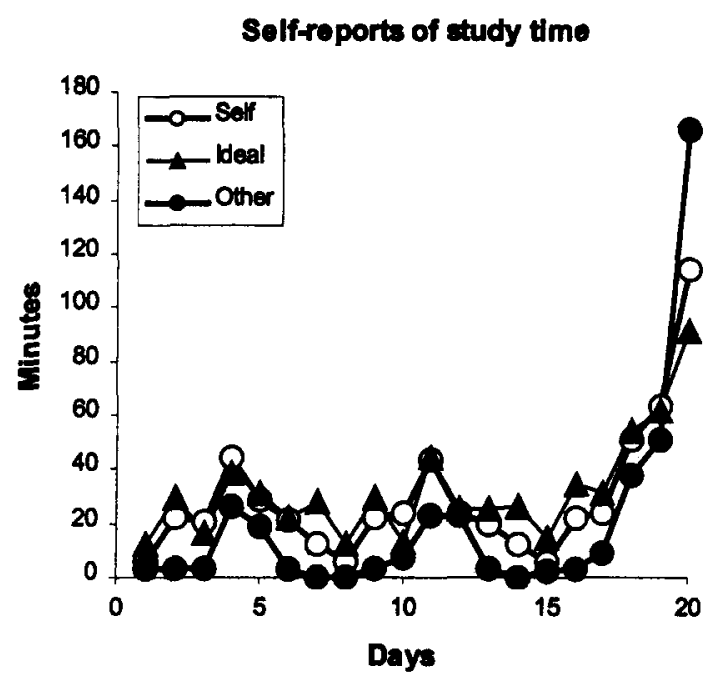

Figure 3. Mean times per student (in minutes) for each of the 20 days between exams for the self, other, and ideal items on the questionnaire. 
Electronic measures from the second and third units were selected for analyses. Unlike the first and last units, each of the middle two units included three chapters and spanned 3 weeks. An electronic mailbox for each chapter contained the records of each quiz submitted. Frequencies of quizzes were extracted for each chapter by date, summed over all the students in the class, and then averaged across the two units. (During these units, 44 students were taking 3-4 quizzes per week.) The Web page counters were sampled at irregular intervals during the entire semester. The count for outline and FAQ pages were extracted for each sample, summed over students, and averaged across the second and third units.

As is shown in Figure 4A, the e-mail records showed that quizzes were submitted most frequently on the 2 days just prior to the weekly deadline. (Although not reported here, the same pattern was shown in the assignment records.) The weekly cycle was observed in the data from each chapter in the unit. Additional quiz taking was observed just prior to the exam, reflecting some use of the system as preparation for the exam. This pattern corresponds to that observed in the self-reports. The students reported spending $70 \%$ of their total study time during the 3 days prior to each deadline; $66 \%$ of the quizzes were taken during those times. The self-reports for self, other, and ideal were all significantly correlated with the summed frequency of quiz taking during the 20 days between exams; correlation coefficients ranged between .50 and .60 [smallest $r(18)=.50, p<.05$ ] .

The analysis of the page counts (hits) for the study materials showed a different pattern. The cumulative frequencies of hits on course outline pages are shown in Figure 4B. Few, if any, hits were recorded on outline pages during the first 2 weeks of each exam cycle. The most hits were recorded during the 2 days immediately preceding the exam (as can be inferred from the difference between samples taken on Day 18 and Day 21 , the exam day). And that was true of each chapter in the unit. The same pattern was found with FAQs. These results show that the study materials were used not as preparation for weekly study, but rather as preparation (cramming) for the exams. In other terms, quiz taking was under the control of the weekly contingencies, but use of study materials was controlled by the exam. It should be noted that the pattern of use of electronic study materials does not result from some general aversion on the part of students to using the materials. Clearly, the materials were used, but were used in ways other than those intended by the designers of the course.

\section{COURSE AND CURRICULUM DESIGN IN THE ELECTRONIC AGE: SOME BEHAVIORAL AND COGNITIVE CONSIDERATIONS}

The three cases reported here reflect a trend toward increasing integration of information technology into college-level instruction. Modern technology, especially
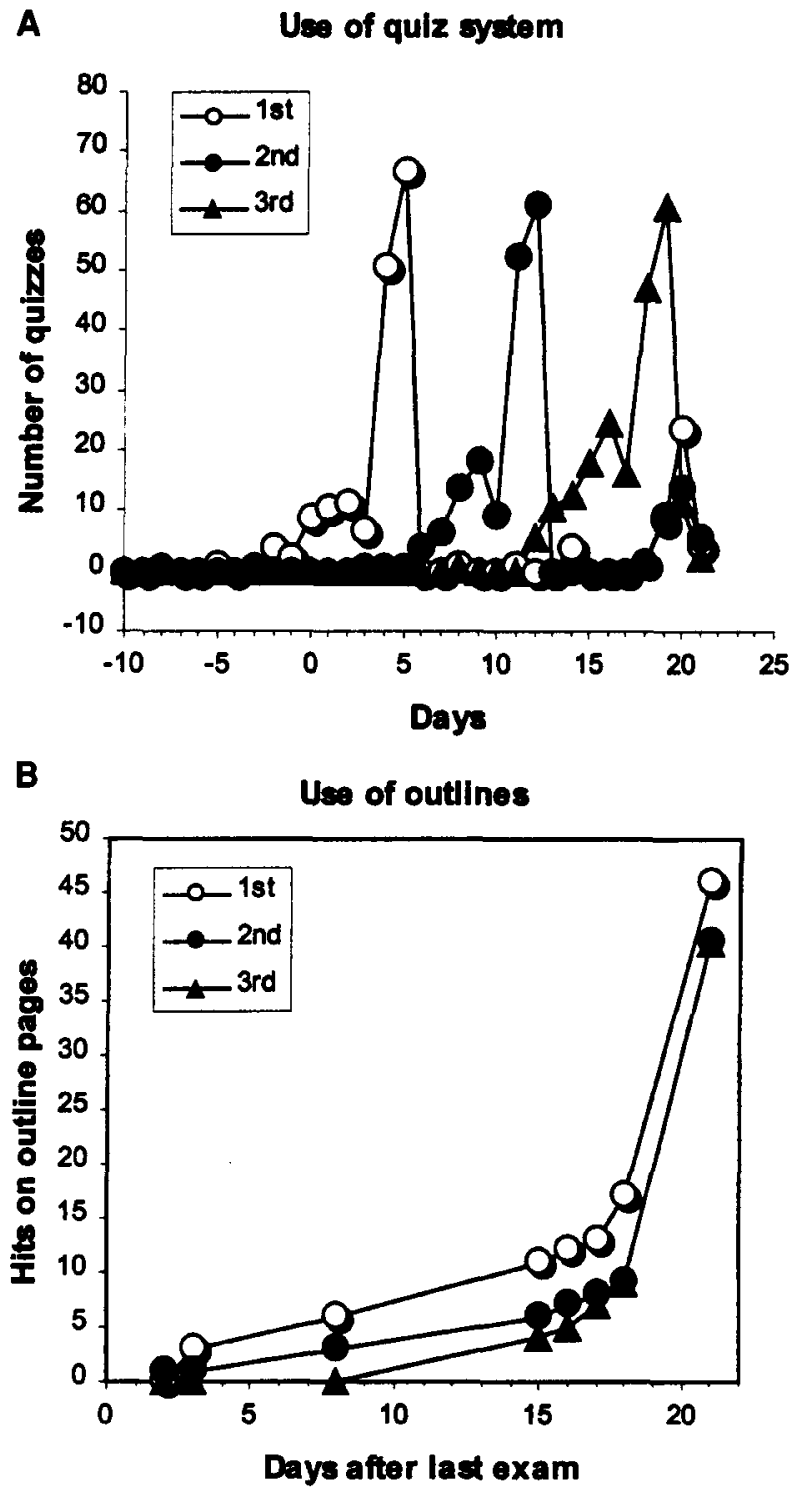

Figure 4. (A) Total number of quizzes taken per day between exams, averaged across two exams. Data are presented for each weekly chapter (1st, 2 nd, 3rd) within each 3 -week period. The peaks correspond to the day prior to the due date for quizzes on each chapter. The additional activity at the end of the 21-day period reflects retakes of quizzes for review purposes prior to the exam on Day 21. (B) Total hits on course outline Web pages. Data are plotted cumulatively only to remove spurious peaks owing to sporadic sampling of the Web page counters. Data are presented for each weekly chapter (1st, 2nd, 3rd) within each 3-week period.

that associated with the WWW, provides capabilities to deliver interactive educational experiences remotely to students both on and off campus. Such experiences can function as supplements (as in Case 2) or substitutes (as in Case 3) for traditional classes that have heretofore been constrained by time and place. As a side effect, this educational technology is providing us with better methods for observing what students do when learning, how much time they spend learning, and how they distribute their 
learning time. In Cases 2 and 3, artifacts of the WWW (such as e-mail headers and Web page counters) and finer grained measures built into specific computer activities were used to monitor how and when students used electronic course materials. In the past, data of this sort were nearly impossible to gather unobtrusively, and it was necessary to rely mostly on self-reports (as in Case 1) or direct observation. Today, technology allows us to collect these data with minimal disruption to learning or inconvenience to students. In addition to measurement of the distribution of study time, the present results are relevant to several educational issues, including how much study time is invested, how it is distributed, mastery learning, and individualized instruction.

The data presented in all three cases suggest that students might not be allocating a great deal of time to learning, regardless of level of technology and course format. Research spanning over 40 years has shown that time spent actively engaged in learning-relevant tasks and achievement are correlated (Borg, 1980). The robustness of these findings across grade levels, schools, and even countries (Bloom, 1974, 1976) suggests that the time factor is powerful enough to override most other factors that affect learning outcomes (e.g., classroom organization). Rigorous measurement, enabled by technology, is a first step toward a program aimed at increasing the time students spend learning.

In all three of the cases, the students reported concentrating their study just before an exam, reported believing that other students did likewise, and expressed the belief that such behaviors were ideal. The self-reports were supported by the analyses of electronic records in Cases 2 and 3. This cramming before an exam may be an efficient means of passing a test (Walberg, 1993), but the material may soon be forgotten. The learning advantage afforded by spacing practice over time, rather than massing it more closely in time, has been well established in the research literature (e. g., H. P. Bahrick, L. E. Bahrick, A. S. Bahrick, \& P. E. Bahrick, 1993). Dempster (1989) noted that "spacing effects are among the most dependable, robust, and ubiquitous phenomena in the entire psychological literature" and that, ultimately, "spacing effects must be transformed into specific educational procedures and techniques that will enhance student learning and achievement" (p. 326). The data presented here suggest that designers of courses should attend to Dempster's advice. The temporal distribution of study behaviors tracks significant course events, such as examinations. In a course environment with a periodic examination schedule, students are unlikely to adopt a spacing strategy on their own. Contingencies will need to be built into the course in order to achieve spaced practice.

According to the basic mastery learning principle, all students can achieve mastery of school tasks by allocating enough learning time (Anderson, 1993; Bloom, 1974, 1976). In principle, virtual classrooms largely eliminate the limits on the time available for learning imposed by traditional educational methods and institutions. This is particularly true when lecture notes, interactive activities, practice quizzes, and primary texts are available over the WWW. Thus, mastery learning may be more feasible than ever before.

The WWW course that is described in Case 3 was originally designed to substitute on-line activities for lectures (W. S. Maki \& R. H. Maki, 1997), but it shares some features with a type of mastery learning - the computer-based Personalized System of Instruction (PSI; Crosbie \& Kelly, 1993). In PSI, course material is divided into small units, and students take formative tests on each unit. Students who fail a unit must retake unit tests until they demonstrate mastery, and learning is self-paced (C. C. Kulik, J. A. Kulik, \& Bangert-Drowns, 1990). Mastery learning programs such as PSI "have positive effects on student achievement" (C. C. Kulik et al., 1990, p. 285). Reorganizing and focusing the topics of the quizzes and instituting a mastery requirement would move the course in Case 3 closer to PSI. Temporal data could be used to investigate the effects of mastery contingencies on distribution of study time in a PSI course like this one, and, conversely, the study time patterns could guide subsequent adjustments of contingencies.

\section{CONCLUSION}

The WWW and related computer technologies provide new opportunities to improve learning at the postsecondary level. The virtual classroom gives students greater flexibility in when they learn, a freedom that will become increasingly important as student demographics and responsibilities outside the school setting continue to change. Virtual lectures, electronic lecture notes, interactive activities, individualized feedback, virtual discussion groups, collaborative learning, and other new formats have vastly extended the repertoire of the teacher and the learner. Importantly, virtual contexts give students better control over their ultimate level of engagement and time commitment and, therefore, their ultimate level of mastery. However, all this potential of educational technology is jeopardized by student adaptations to traditional course organization. The data we have gathered in three different contexts suggest that students do not grasp the connection between time and learning, view other students as similar to themselves with respect to learning and mastery, believe that massed practice is an ideal distribution of study time, and behave consistently with those cognitions. In this paper, we have reported on the first steps toward using technology to effectively restructure our educational practices - namely, by measuring student use of electronic course materials. The emerging methods of collecting temporal data unobtrusively will allow better monitoring of student behavior and instructional effectiveness, will provide us with the means to establish contingencies to get students interacting with course materials in temporally more beneficial ways, and will enable a 
research agenda in which we evaluate the effects of technological innovations on student academic behaviors and learning.

\section{REFERENCES}

ANDERson, L. W. (1993). What time tells us. In L. W. Anderson \& H. J. Walberg (Eds.), Timepiece: Extending and enhancing learning time (pp. 15-32). Washington, DC: National Association of Secondary School Principals.

Bahrick, H. P., Bahrick, L. E., Bahrick, A. S., \& Bahrick, P. E. (1993). Maintenance of foreign language vocabulary and the spacing effect. Psychological Science, 4, 316-322.

BARR, R., \& TAGG, J. (1995). From teaching to learning: A new paradigm for undergraduate education. Change, 27, 12-25.

BLoom, B. S. (1974). Time and learning. American Psychologist, 29, 682-688.

BLOOM, B. S. (1976). Human characteristics and school learning. New York: McGraw-Hill.

BoRG, W. R. (1980). Time and school learning. In C. Denham \& A. Lieberman (Eds.), Time to learn (pp. 33-72). Washington, DC: U.S. Department of Education.

BORK, A. (1997). The future of computers and learning. Technological Horizons in Education, 24, 69-77.

Crosbie, J., \& Kelly, G. (1993). A computer-based Personalized System of Instruction course in applied behavior analysis. Behavior Research Methods, Instruments, \& Computers, 25, 366-370.
DEDE, C. (1996). The evolution of distance education: Emerging technologies and distributed learning. American Journal of Distance Education, 10, 4-36.

DEMPSTER, F. (1989). Spacing effects and their implications for theory and practice. Educational Psychology Review, 1, 309-330.

Kulik, C. C., Kulik, J. A., \& BANGERT-Drowns, R. L. (1990). Effectiveness of mastery learning programs: A meta-analysis. Review of Educational Research, 60, 265-299.

MAKI, W. S., \& MAKI, R. H. (1997). Learning without lectures: A case study. IEEE Computer, 30, 107-108.

SchWARTZ, A. (1998). Tutorial: Perl, a psychologically efficient reformatting language. Behavior Research Methods, Instruments, \& Computers, 30, 605-609.

STEIN, L. (1998). Official guide to programming with CGI.pm. New York: Wiley.

TARABAN, R., \& RYNEARSON, K. (1998). Computer-based comprehension research in a content area. Journal of Developmental Education, 21, 10-18.

WALberG, H. J. (1993). Productive use of time. In L. W. Anderson \& H. J. Walberg (Eds.), Timepiece: Extending and enhancing learning time (pp. 1-8). Washington, DC: National Association of Secondary School Principals.

Wall, L., Chistiansen, T., \& Schwartz, R. L. (1998). Programming Perl (2nd ed.). Sebastopol, CA: O'Reilly \& Associates.

(Manuscript received December 14, 1998; revision accepted for publication March 3, 1999.) 